DOI: 10.12731/2227-930X-2017-2-74-97

УДК 378.046.4

\title{
ПОВЫШЕНИЕ КВАЛИФИКАЦИИ ПЕДАГОГИЧЕСКИХ И РУКОВОДЯЩИХ РАБОТНИКОВ ОБРАЗОВАТЕЛЬНЫХ ОРГАНИЗАЦИЙ РЕСПУБЛИКИ АДЫГЕЯ В УСЛОВИЯХ РЕАЛИЗАЦИИ НОВЫХ СТАНДАРТОВ
}

\section{Шехмирзова А.М., Грибина Л.В., Тугуз Ф.А.}

В условиях введения стандартов нового поколения, перед российскими образовательными организачиями встали задачи, связанные с модернизацией системь повымения квалификации педагогических и руководящих работников.

Изучение состояния образовательной практики повышения квалификации педагогических и руководящих кадров к осуществлению инновационной деятельности в соответствии с требованиями новых стандартов, показало, что она не может гибко реагировать на изменения запросов современного социума и обеспечить высокое качество образования. Основные причины практических затруднений связаны с отсутствием иелостной системы повышения квалификации педагогических и руководящих работников общего и профессионального образования к реализациии требований стандартов нового поколения при условии координированного их коллективного взаимодействия.

Цель исследования - представление инновационной модели повышения квалификации педагогических кадров и руководящих работников системы общего и профессионального образования на территории Республики Адыгея, ориентированной на обеспечение их готовности к реализаџии требований новых стандартов с учетом Национальной системы учительского роста.

Метод или методология проведения работы: в статье представлен комплекс теоретических и эмпирических методов педагогического исследования. 
Результаты: в контексте инновационной модели выявлены уровни готовности педагогических и руководящих работников системь общего и профессионального образования на территории Республики Адыгея к инноващионной деятельности по реализации требований стандартов нового поколения с учетом Национальной системь учительского роста.

Область применения результатов: результаты проведенного исследования могут послужить основой управленческой стратегии образовательных организаций на территории Республики Адыгея при решении актуальных задач по реализации планируемых результатов обучения в соответствии с требованиями новых стандартов и повышения качества общего и профессионального образования.

Ключевые слова: стандарты общего и профессионального образования; готовность педагогических и руководящих кадров системь общего и профессионального образования; готовность к инновационной деятельности; инновационная модель повышения квалификации; планируемыле образовательныле результатьі; кадровые и инье условия реализации требований стандартов нового поколения; качество общего и профессионального образования.

\section{PROFESSIONAL DEVELOPMENT PEDAGOGICAL AND EXECUTIVES OF THE EDUCATION ORGANIZATIONS OF THE REPUBLIC OF ADYGEA TO IMPLEMENTATION OF NEW STANDARDS}

\section{Shekhmirzova A.M., Gribina L.V., Tuguz F.A.}

In the context of introduction of standards of a new generation, before the Russian education organizations there were tasks connected with modernization of system of professional development pedagogical and executives.

Studying of a condition of education practice of professional development of the pedagogical and managerial personnel to imple- 
mentation of innovative activities according to requirements of new standards, showed that it can't flexibly react to changes of requests of modern society and provide high quality of education. Basic reasons of practical difficulties are connected with lack of complete system of professional development of pedagogical and leading employees of the general and vocational education to implementation of requirements of standards of new generation on condition of their coordinate collective interaction.

The purpose of research - presentation of an innovative model of training and retraining of teachers and executives of the educational system in Republic of Adygea, focused on ensuring their readiness for implementation of the requirements of the new standards taking into account the National System of Teacher Growth.

Method or methodology of work: in the article presents a set of theoretical and empirical methods of pedagogical research.

Results: in the context of the innovation model the levels of readiness of pedagogical and managerial staff of the system of general and professional education in the territory of the Republic of Adygea to innovative activities to implement the requirements of the new generation standards are revealed taking into account the National System of Teacher Growth.

Practical implications: The results of the study can form a basis to the managerial strategy of the general education organizations in Republic of Adygea in case of the solution of urgent tasks on implementation of the planned results of training according to requirements of new standards and improvement of quality of the general education.

Keywords: standards of the general and vocational education; readiness of the pedagogical and managerial personnel of system of the general and vocational education; readiness for innovation; innovative model of professional development; the planned educational results; personnel and other sales terms of requirements of standards of new generation; quality of the general and vocational education. 


\section{Введение}

Модернизационные процессы в системе повышения квалификации (ПК) педагогических и руководящих работников, обусловленные введением новых стандартов, поставили перед образовательными организациями (ОО) актуальные задачи разработки образовательных программ и определения технологий их реализации.

Изучение состояния образовательной практики ПК педагогических и руководящих кадров к осуществлению инновационной деятельности показало невозможность решения новых задач современного социума без гибкого реагирования социальными институтами образования различного уровня на изменения ее запросов. В ходе нашего исследования было выявлено, что ОО в своем большинстве сталкиваются с практическими затруднениями, связанными с отсутствием целостной системы ПК педагогических и руководящих работников общего и профессионального образования к реализации требований стандартов нового поколения. Все они обусловлены тенденциями современного образования и ситуацией на рынке труда, определяющие необходимость своевременного пополнения ими багажа знаний достижениями науки и практики, невозможного без систематического ПК. Именно поэтому, не только педагогические, но и руководящие работники ОО любого уровня, должны развивать и совершенствовать профессиональный и личностный потенциал. Необходимость этого нашло нормативное закрепление в образовательных и профессиональных стандартах (Профессиональном стандарте «Педагог (педагогическая деятельность в сфере дошкольного, начального общего, основного общего, среднего общего образования) (воспитатель, учитель)», утвержденном Приказом Минтруда России № 544н от 18.10.2013 (далее - ПС Педагог); проекта ПС «Руководитель образовательной организации»), в которых выделяются новые аспекты развития профессиональных компетенций педагогических и руководящих работников, в том числе, развитие управленческих и лидерских навыков, компетентности создания высокопроизводительной педагогической и исследовательской команды. 
Обобщение уровня изученности сущности проблемы ПК руководящих и педагогических кадров, степени ее практической разработанности на федеральном, региональном, муниципальном и школьном уровнях, позволило заключить, что, несмотря на имеющийся определенный объем научных работ, значительные усилия руководящих и педагогических работников общего и профессионального образования, требуется качественное преобразование системы ПК и изменение подходов к реализации положений образовательного и профессионального стандартов с учетом Национальной системы учительского роста.

Осуществление инновационной деятельности по реализации новых стандартов требует качественных изменений в ОО как педагогической системы, проектирование которой предполагает модернизацию всех ее компонентов с учетом объективных потребностей и возможностей, обеспечивающие системные (а не фрагментарные) преобразования. Как показали авторские исследования последних годов, в большинстве российских ОО проводятся фрагментарные изменения под давлением вышестоящих управленческих органов образования, приводящие к имитированию инновационной деятельности. В них отсутствуют эффективные системы управления инновационной деятельностью по реализации новых стандартов.

Отсутствие целостной системы управления инновационной деятельностью педагогических и руководящих работников общего и профессионального образования, как на федеральном, так и на региональном уровнях, не ориентировано на обеспечение готовности ОО к реализации требований стандартов нового поколения.

Недостаточная разработанность в педагогической литературе и практическая потребность регионального образования в научно-обоснованном управлении инновационной деятельностью ОО как педагогической системы, ориентированной на обеспечение их готовности к реализации новых стандартов, определило актуальность проводимого исследования. 


\section{Цель исследования}

Целью эмпирического исследования является верификация теоретически обоснованных положений по определению уровня готовности ОО в рамках разработанной инновационной модели целостной системы управления ПК педагогических и руководящих работников по реализации новых стандартов в условиях сетевого регионального объединения ОО.

Для достижения данной цели в ходе исследования на основе комплекса адекватных исследовательских методов были решены две задачи: 1) выявление уровня готовности ОО к осуществлению инновационной деятельности по реализации новых стандартов с учетом запросов современного времени; 2) апробация проекта готовности ОО к инновационной деятельности по реализации новых стандартов.

Результаты эмпирического исследования стали основой научно-обоснованной разработки инновационной модели целостной системы управления ПК педагогических и руководящих работников в условиях сетевого регионального объединения образовательных организаций на основе применения современных информационно-коммуникационных технологий (ИКТ), обеспечивающих их готовность к качественному осуществлению профессиональной деятельности.

\section{Материалы и методы исследования}

Отдельные практические результаты проводимого исследования отражены в различных авторских публикациях последних лет [8; 9]. Представленные в данной работе материалы отражают промежуточные результаты относительно самостоятельного исследования проблемы ПК педагогических и руководящих кадров на территории РА с учетом современных тенденций управления системой российского образования. Описанный в статье региональный опыт проводимой в РА политики в сфере образования характеризует управленческую стратегию развивающейся целостной системы педагогических и руководящих работников об- 
разования в условиях сетевого регионального объединения ОО с применением ИКТ и ресурсов сети Интернет.

Изложенные в статье промежуточные результаты исследования готовности ОО к инновационной деятельности по реализации новых стандартов проводилось в рамках разработки инновационной модели целостной системы управления ПК педагогических и руководящих работников системы регионального образования в условиях сетевого регионального объединения ОО, ориентированной на совершенствование системы управления их развитием. Переход ко второму этапу исследования, связанного с апробацией этой инновационной модели ПК целостной системы управления ПК педагогических и руководящих работников образования, позволяет сделать предварительное умозаключение об эффективности проводимой работы, результаты которой будут опубликованы в дальнейших авторских публикациях.

В соответствии с поставленной целью и исследовательскими задачами проводимой работы используется комплекс методов педагогического исследования: теоретических - анализ педагогической и научно-методической литературы по проблеме исследования, изучение и анализ нормативно-правовых актов и локальных документов по вопросам повышения квалификации и педагогических и руководящих работников системы общего и профессионального образования, анализ результатов мониторинговых исследований Лаборатории мониторинга и статистики образования АРИПК, теоретическое обобщение результатов на различных этапах исследования; эмпирических - изучение и обобщение педагогического опыта реализации требований новых стандартов, педагогическая беседа и наблюдение за деятельностью педагогов образовательных организаций РА в ходе различных федеральных и региональных конкурсов («Новой школе новые учителя», «Учитель года»), прохождения курсов ПК по вопросам реализации ФГОС в соответствии с планом работы Министерства образования и науки РА, опросные методы с участием бакалавров и магистрантов АГУ, проектирование готовности ОО 
к инновационной деятельности по реализации новых стандартов; моделирование (разработка инновационной модели целостной системы управления ПК педагогических и руководящих работников на территории РА); методы количественной и качественной обработки эмпирических данных.

Теоретическое обоснование проблемы ПК педагогических и руководящих работников довольно широко освещено в публикациях таких исследователей, управленцев, как Т.И. Шамова, К.А. Нефедова, Г.Н. Сериков, И.О. Котлерова, Н.А. Горчарова, А.И. Дарвинский, А.И. Пескунова, В.Н. Турчинка, А.К. Ellis, I.K. Hassard, J.H. Hassard, J.D. Wohnson, R.T. Johnson, F.E. Sayyida, G.K. Attaollah и др. Целесообразность и возможность применения программно-целевого принципа в управлении повышением квалификации педагогических работников обосновываются в работах С.Г. Молчанова, Д.Ф. Ильясова, В.П. Ворошиловой, В.А Худякова, В.В. Давиденко и др. Исследование в области ПК педагогических и руководящих кадров представлено в трудах В.Г. Воронцовой, Н.М. Зверевой, Е.Г. Овчинниковой, М.М. Поташника, К.М. Ушакова и др. Различные подходы к ПК в условиях сетевого взаимодействия образовательных организаций исследованы в психолого-педагогических работах А.И. Адамского, А.Г. Заляловой, Д.А. Новикова, Д.В. Смирнова и др. Опыт управления системой ДПО представлен в работах Н.Г. Калашниковой, И.Р. Лазаренко, Л.А. Мокрецовой, Т.И. Шамовой, В.Я. Синенко и др.

Как показал анализ педагогической и научно-методической литературы по проблеме исследования, изучение действующих моделей ПК, анализ нормативно-правовых и локальных документов по вопросам повышения квалификации и педагогических и руководящих работников системы общего и профессионального образования, анализ результатов мониторинговых исследований Лаборатории мониторинга и статистики образования АРИПК, в большинстве российских учреждений (организаций) дополнительного профессионального образования (ДПО) реализуется традиционная модель ПК с присущими ей методами и нейропсихофизиологиче- 
скими механизмами обучения, мало способствующими формированию профессиональных компетенций в соответствии с потребностями современного общества и требованиями нормативно-правовых актов в сфере общего и профессионального образования.

В условиях введения новых стандартов в системе общего и профессионального образования возрастает необходимость усиления практической направленности образовательного процесса в организациях общего и профессионального образования, внесение изменений в технологию и механизмы его реализации $[1 ; 2 ; 5$; 7]. Практико-ориентированная подготовка работников образования и будущих педагогов имеет целью формирование их готовности к осуществлению инновационной деятельности по реализации новых стандартов, развитие их способности к самостоятельному профессиональному росту с учетом запросов современного времени в условиях конкретной ОО. Общность проблем реализации практико-ориентированного подхода в организациях общего и профессионального образования предполагает установление между ними тесного взаимосотрудничества. Функционирование партнерских взаимоотношений между школой, вузом и ДПО с использованием сетевой формы позволяет перейти на качественно новый уровень $[10 ; 11 ; 12 ; 13 ; 14 ; 15]$.

Проведенный анализ педагогического опыта, практики работы общеобразовательных школ, статистических данных Лаборатории мониторинга и диагностики АРИПК, результатов входного и выходного анкетирования учителей-практиков, молодых педагогов, руководителей ОО, принимающих участие с 2013 года в реализации ФГОС, показал невысокий уровень готовности педагогических и руководящих кадров к осуществлению инновационной деятельности, к реализации требований новых стандартов. Несмотря на массовое ПК педагогических кадров и руководящих работников общего образования в рамках перехода общеобразовательных школ на новые ФГОС, существенной модернизации самой образовательной системы не произошло. Очевидно, что для модернизации образовательной практики требуются существенные изменения в самих ОО как педагогической системы. Исходя из этого, 
исходными теоретическими представлениями, нашедшими практическое обоснование в результате эмпирического исследования, стало положение о том, что уровень готовности ОО к инновационной деятельности зависит от того, насколько адекватно понимаются руководящими и педагогическими работниками требуемые для эффективной реализации новых стандартов изменения в системе управления модернизационными процессами. Они призваны стать основой для перехода ОО на новое качество образования.

Для этого, мы предположили, что инновационная деятельность будет осуществляться качественно педагогическими и руководящими работниками, если обеспечивается модернизация всех компонентов педагогической системы с учетом объективных потребностей и возможностей. Качество инновационной деятельности при реализации новых стандартов становится тем выше, чем более адекватны объективным потребностям и возможностям внесённые преобразования в различные компоненты педагогической системы ОО: в образовательные цели и способы их оценивания, в содержании образовательных программ, в применяемые образовательные технологии, в информационно-образовательную среду (ИОС). То есть, качество инновационной деятельности по реализации новых стандартов зависит от того, как ОО оценивают необходимость внедряемых изменений путем сопоставления с потребностями и возможностями своего развития, как выявляют возникающие при этом затруднения и как оценивают используемые способы их преодоления.

Реализация этой инновационной деятельности по введению новых стандартов предполагает решение следующих педагогических задач: 1) выявление актуальных потребностей преобразований в ОО как педагогической системы; 2) определение имеющихся возможностей для требуемых преобразований; 3) планирование модернизации всех компонентов педагогической системы с учетом объективных потребностей и возможностей. При этом, эффективность решения этих задач и качество инновационной деятельности по реализации новых стандартов обуславливается уровнем готовности ОО к соответствующим действиям. 
В нашем исследовании готовность ОО к инновационной деятельности по реализации новых стандартов определяется в виде интегративной характеристики ее состояния как педагогической системы с составляющими компонентами (целевой, содержательный, процедурный, организационно-управленческий). Все компоненты предполагают готовность ОО к модернизации структурных составляющих образовательного процесса ПК педагогических и руководящих работников сферы образования: образовательные цели и способы их оценивания, содержание образовательных программ, применяемые образовательные технологии, ИОС (рис. 1). Отсюда компонентами готовности ОО как интегративной характеристики выступают:

- готовность к модернизации целевого компонента, предполагающего приведение образовательных целей в соответствие с имеющимися потребностями и возможностями ОО;

- готовность к модернизации содержательного компонента, связанного с обновлением содержания образовательных программ курсов ПК;

- готовность к модернизации процедурного компонента, предусматривающего усовершенствование способов оценивания образовательных целей и применяемых образовательных технологий.

- готовность к модернизации организационно-управленческого компонента, определяющего создание благоприятной ИОС.

Используемые в нашем исследовании интегративные характеристики выделены согласно рекомендациям Ю.С.Тюнникова по проектированию интегративных педагогических процессов. При выборе блочного построения проектируемого процесса готовности ОО к инновационной деятельности нами было принято во внимание продуктивность такого представления, предложенного А.А.Кирсановым и Ж.А.Зайцевой по моделированию процесса обучения.

Выделенные нами компоненты педагогической системы (целевой, содержательный, процедурный, организационно-управленческий) вошли в состав трех блоков: ориентировочного, организационного, технологического. 


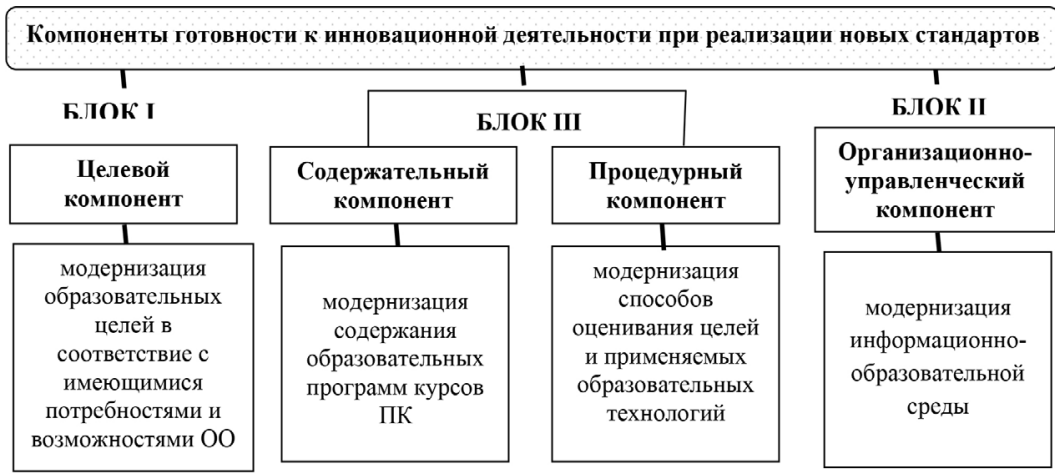

Показатели готовности к инновационной деятельности при реализации новых стандартов

\begin{tabular}{|c|c|c|c|}
\hline $\begin{array}{c}\text { адекватное } \\
\text { понимание } \\
\text { потребных } \\
\text { преобразований } \\
\text { целей в } \\
\text { соответствие с } \\
\text { имеющимися } \\
\text { потребностями и } \\
\text { возможностями }\end{array}$ & $\begin{array}{c}\text { адекватное } \\
\text { понимание } \\
\text { потребных } \\
\text { преобразований } \\
\text { содержания } \\
\text { образовательных } \\
\text { программ курсов } \\
\text { ПК }\end{array}$ & $\begin{array}{c}\text { адекватное } \\
\text { понимание } \\
\text { потребных } \\
\text { преобразований } \\
\text { способов } \\
\text { оценивания целей } \\
\text { и применяемых } \\
\text { образовательных } \\
\text { технологий }\end{array}$ & $\begin{array}{c}\text { адекватное } \\
\text { понимание } \\
\text { потребных } \\
\text { преобразований } \\
\text { информационно- } \\
\text { образовательной } \\
\text { среды }\end{array}$ \\
\hline $\begin{array}{c}\text { адекватное } \\
\text { понимание } \\
\text { возникающих при } \\
\text { осущсствлении } \\
\text { целей } \\
\text { затруднений }\end{array}$ & $\begin{array}{c}\text { адекватное } \\
\text { понимание } \\
\text { возникающих при } \\
\text { реализации } \\
\text { содержания } \\
\text { образовательных } \\
\text { программ курсов } \\
\text { ПК затруднений }\end{array}$ & $\begin{array}{c}\text { адекватное } \\
\text { понимание } \\
\text { возникающих при } \\
\text { применении } \\
\text { способов } \\
\text { оценивания целей и } \\
\text { образовательных } \\
\text { технологий } \\
\text { затруднений }\end{array}$ & $\begin{array}{c}\text { адекватное } \\
\text { понимание } \\
\text { возникающих при } \\
\text { создании ИОС } \\
\text { затруднений }\end{array}$ \\
\hline $\begin{array}{c}\text { адекватное } \\
\text { понимание } \\
\text { используемых } \\
\text { способов } \\
\text { преодоления } \\
\text { затруднений при } \\
\text { реализации целей }\end{array}$ & $\begin{array}{c}\text { адекватное } \\
\text { понимание } \\
\text { используемых } \\
\text { способов } \\
\text { преодоления } \\
\text { затруднений при } \\
\text { реализации } \\
\text { содержания } \\
\text { образовательных } \\
\text { программ курсов ПК }\end{array}$ & $\begin{array}{c}\text { адекватное } \\
\text { понимание } \\
\text { используемых } \\
\text { способов } \\
\text { преодоления } \\
\text { затруднений при } \\
\text { оценивании целей и } \\
\text { использовании } \\
\text { образовательных } \\
\text { технологий }\end{array}$ & $\begin{array}{c}\text { адекватное } \\
\text { пониманис } \\
\text { используемых } \\
\text { способов } \\
\text { преодоления } \\
\text { затруднений } \\
\text { возникающих при } \\
\text { создании ИОС }\end{array}$ \\
\hline
\end{tabular}

Рис. 1. Модель готовности ОО к инновационной деятельности 
I. Ориентировочный блок составляет иелевой компонент, отражающий педагогическую направленность, общий замысел, сопряженность целей по выделенным показателям и функциональную значимость готовности ОО к инновационной деятельности по реализации новых стандартов для достижения конкретных результатов.

II. Организационный блок составляет организационно-управленческий компонент, предполагающий создание программы готовности ОО к инновационной деятельности по реализации новых стандартов, координацию и кооперацию педагогических и руководящих работников с органами управления и другими ОО, использование ИКТ.

III. Технологический блок составляют содержсательный и процедурный компоненты. Содержсательный компонент дает представление об особенностях оценки готовности ОО к инновационной деятельности по реализации новых стандартов на основе выделенных показателей, его логико-содержательной основе, элементах, уровнях и масштабах. Процедурные характеристики дают возможность представить совокупность способов, средств, приемов и форм организации процедуры оценки готовности ОО к инновационной деятельности по реализации новых стандартов.

Показателями готовности ОО к инновационной деятельности по реализации новых стандартов и модернизации ее составных компонентов выступают:

- адекватное понимание внесенных изменений в каждый из составляющих компонентов педагогической системы в соответствии с ее объективными потребностями и возможностями;

- адекватное понимание возникающих затруднений при качественном внедрении преобразований;

- адекватное понимание используемых способов их преодоления.

Оценивание готовности ОО к инновационной деятельности по реализации новых стандартов основывалось на разработанном инструментарии (с показателями, критериями, шкалами), став- 
шим эффективным средством сравнительного анализа для определения их различий.

Данные суждения стали основой нашей гипотезы о том, что научно-обоснованное проектирование готовности ОО к инновационной деятельности по реализации новых стандартов, определяемое в виде интегративной характеристики ее состояния как педагогической системы с составляющими компонентами (целевой, содержательный, процедурный, организационно-управленческий) и с показателями оценивания по составленному инструментарию, в рамках разработанной инновационной модели целостной системы управления ПК педагогических и руководящих работников в форме сетевого регионального объединения ОО, служит эффективным средством сравнительного анализа для определения их различий.

Данная гипотеза нашла практическое обоснование в ходе эмпирического исследования готовности ОО к инновационной деятельности по реализации новых стандартов, результаты которого стали основой для научной разработки инновационной модели целостной системы управления ПК педагогических и руководящих работников системы регионального образования, ориентированной на совершенствование системы управления их развитием (рис. 2).

На констатирующем этапе опытно-экспериментальной работы исходный уровень готовности ОО к инновационной деятельности по реализации новых стандартов определялся на основе данных анкетного опроса педагогических и руководящих кадров, работников органа управления образованием. Формирование вопросов анкеты основывалось на инструментарии оценки готовности ОО к инновационной деятельности.

Оценка готовности к модернизации целевого, содержательного, процедурного, организационно-управленческого компонентов педагогической системы осуществлялась по соответствующим показателям на основе суждений респондентов. В качестве дополнительной информации использовались данные опросных методов, полученные с участием бакалавров и магистрантов АГУ, 
педагогической беседы и наблюдения за деятельностью педагогов ОО РА в ходе различных федеральных и региональных конкурсов («Новой школе - новые учителя», «Учитель года»), прохождения курсов ПК по вопросам реализации ФГОС в соответствии с планом работы Министерства образования и науки РА [3; 6].

Не останавливаясь на основных результатах эмпирического исследования, описанных в нижеследующем разделе статьи, здесь кратко представим основанные на этих данных отдельные исследовательские материалы, на основе которых разрабатывалась инновационная модель целостной системы управления ПК педагогических и руководящих работников образования.

При разработке инновационной модели были учтены трудности практики обучения в реализации требований новых стандартов в соответствии с запросами современного общества, выявленные на основе комплекса эмпирических методов (педагогическая беседа, наблюдение за деятельностью педагогических и руководящих работников ОО РА, опросные методы). Значимость разработанной авторами инновационной модели, предусматривающей создание ИОС с применением ресурсов сетевого объединения ОО, возрастает в условиях происходящих изменений в российской системе общего и профессионального образования с учетом Национальной системы учительского роста (НСУР)[4; 12]. Безусловно, что использование ресурсов сетевого объединения ОО содержит мощные механизмы для реализации целевых установок образовательных и профессиональных стандартов в контексте социализации всех участников образовательного процесса. Комплексный подход к моделированию процесса ПК в форме сетевого объединения ОО делает возможным создание целостной региональной системы управления ПК педагогических и руководящих работников в соответствии с вызовами современного времени и НСУР, разрешающей трудности сопряжения документов в сфере педагогического образования путем установления дифференциации уровней владения профессиональными компетенциями с учётом сложности их овладением. 


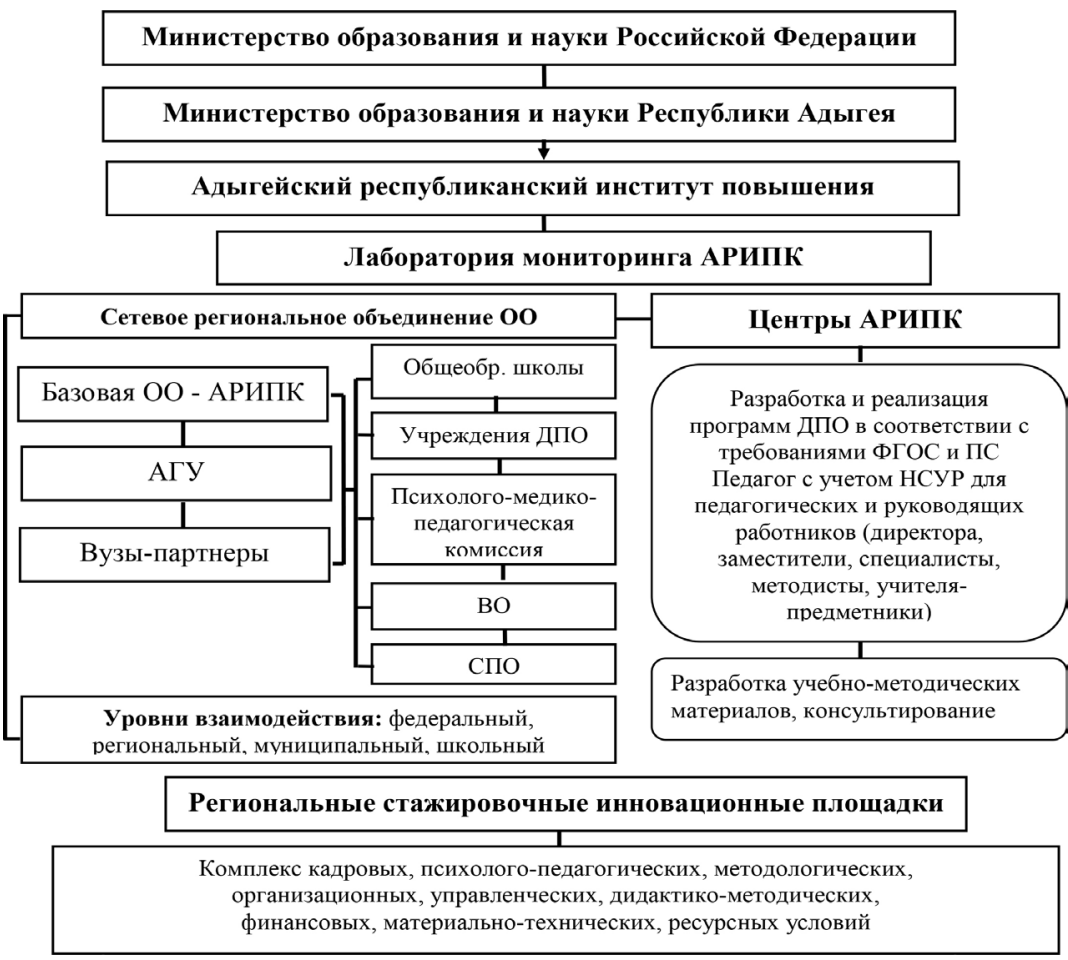

Рис. 2. Инновационная модель целостной системы управления повышением квалификации педагогических и руководящих работников в условиях сетевого регионального объединения образовательных организаций

На необходимость наличия в каждом регионе РФ качественно работающих институтов ПК педагогов обратила внимание глава Минобрнауки РФ О. Васильева на прошедшей в Сочи в начале текущего года межрегиональной конференции «Развитие единой системы оценки качества образования: опыт и перспективы» [4].

\section{Результаты исследования и их обсуждение}

С учетом незавершенности проводимой реформации в сфере российского образования (введение ПС Педагога, наряду с реализацией ФГОС, и становление НСУР) и продолжающейся работы 
авторов, в статье представлены промежуточные результаты исследования, определяющие формирование управленческой стратегии опережающей модернизации общего и профессионального образования на территории РА.

В ходе эмпирического исследования выявлены статистически значимые различия уровня готовности педагогических и руководящих работников к инновационной деятельности, обусловленные различиями в готовности ОО к модернизации системы управления различными аспектами педагогической системы (по показателям готовности к обновлению ее компонентов). Определение уровня готовности ОО к инновационной деятельности по различным показателям осуществлялось по разработанному инструментарию на основе суммирования баллов по соответствующим показателям. Общий балл готовности ОО к инновационной деятельности рассчитывался по интегральной шкале.

Определение различий между ОО в готовности к инновационной деятельности по реализации новых стандартов проводилось по статистическому критерию Краскала-Уоллиса. Полученные статистические данные позволили выделить группы ОО с различным уровнем готовности к инновационной деятельности (высокий $-10 \%$; средний $-40 \%$; низкий $-52 \%$ ) на основе результатов соответствующих компонентов.

Выявление основных причин практических затруднений ОО к реализации инновационной деятельности по введению новых стандартов позволило выделить статистически значимо различающиеся уровни по каждому из параметров. На основе критерия $\mathrm{x}^{2}$ Пирсона и Н-критерия Краскала-Уоллиса проводилась оценка значимости различий по выделенным группам ОО с разными уровнями готовности, показавшая надежность различий по соответствующим параметрам.

В результате эмпирического исследования была установлена связь готовности ОО к инновационной деятельности по реализации новых стандартов с интенсивностью преобразований по целевому, содержательному, процедурному, организационно- 
управленческому компонентам педагогической системы, обусловившая необходимость разработки целостной системы управления ПК педагогических и руководящих работников в условиях сетевого регионального объединения ОО.

\section{Заключение}

В заключении отметим, что полученные результаты эмпирического исследования подтвердили справедливость выдвинутой гипотезы о зависимости уровня готовности ОО к инновационной деятельности от адекватного понимания руководящими и педагогическими работниками требуемых для эффективной реализации новых стандартов преобразований в различных компонентах педагогической системы и осознания возникающих практических затруднений из-за отсутствия целостной системы управления ПК. Результаты эмпирического этапа исследования призваны стать основой для перехода системы общего и профессионального образования РА на качественно новый уровень. Для этого разработана авторская инновационная модель целостной системы управления ПК педагогических и руководящих работников в форме сетевого регионального объединения ОО РА с применением современных ИКТ и сети Интернет.

Развитие целостной системы управления ПК педагогических и руководящих работников образования в РА способствует повышению уровня их готовности к реализации требований стандартов нового поколения с учетом становящейся НСУР. Инновационная модель соответствует проводимой в стране единой государственной политике в области общего и профессионального образования, зафиксированной в ФЗ «Об образовании в РФ». В контексте этого значимого нормативно-правового акта, именно с эффективностью систем регионального образования связываются успехи в социально-экономической, политической, международной областях. Отсюда Федеральная и региональная программы образования до 2020 года являются организационно-управленческой основой государственной политики в области общего и профессионального образования в РА. 
Представленные в статье промежуточные результаты исследования не исчерпывают решение поставленной проблемы и служат основой управленческой стратегии ОО на территории РА при решении актуальных управленческих задач в образовательной сфере в контексте НСУР и формирования инновационной инфраструктуры в сфере образования при Минобрнауки РА.

\section{Сиисок литературы}

1. Шехмирзова А.М. О необходимости проектирования новой педагогической системы и реализации педагогической технологии в соответствии с компетентностным подходом // Современное образовательное пространство: пути модернизации: материалы II международной заочной научно-практической конференции. 5 декабря 2011/ Научный редактор М.В. Волкова. Чебоксары: НИИ педагогики и психологии, 2011. 222 с. С. 214-218.

2. Шехмирзова А.М., Пшизова А.Р. Методологические проблемы вузовской практики формирования универсальных компетенций (на примере педагогических и экономических направлений подготовки) // В мире научных открытий. № 11.4 (71), 2015. С. 1498-1508.

3. Аверин С.П. Социально-педагогический мониторинг как условие совершенствования деятельности ИПК РО по повышению квалификации работников образования в регионе. Красноярск: ИПК PO, 2001. 154 c.

4. Информационное Агентство России «ТАСС» [Электронный ресурс]: офиц. сайт. Режим доступа: http://tass.ru/opinions/interviews/3615515 (дата обращения: 02.12.2016).

5. Перечень поручений по итогам заседания Государственного совета по вопросам совершенствования системы общего образования от 23.12. 2015 г. - [Электронный ресурс]: офиц. сайт. Режим доступа: http://www.kremlin.ru/events/state-council/51143 (дата обращения: 03.02.2017).

6. ФГБНУ «Институт стратегии развития образования Российской академии образования» [Электронный ресурс] / М-во образования и науки РФ. Режим доступа: http://www.instrao.ru 
7. Denise Vaillant Teacher training in Latin America. Models and tendencies conference «Priorites-Priorities-Prioridades». November 15 to 17, 2000. Paris. 20 p. URL: http://www.denisevaillant.com/articulos/2000/priorites2000ENG.pdf

8. Ellis A.K. Research on Educational Innovations / A.K. Ellis, J.T. Fouts. N.Y.: Eye On Education: Princeton Junction, 1993, pp. 189-202.

9. Hassard I. Creating Cooperative Learning Environments. Menlo Рагк. California, $1987.92 \mathrm{p}$.

10. Hassard J. Creating Cooperative Learning Invironment. Menlo Park, California, 1997. $126 \mathrm{p}$.

11. Johnson D.W., Johnson R.T. Learning together and alone: Cooperation, competition and individualization. Englewood Cliffs (N.3.), 1980.

12. Sayyida F.E., Attaollah G.K. Comparative Study of Information and Communication Technology Development Strategies in Primary Education of America, Australia and Iran. // International Journal of Basic Sciences \& Applied Research. Vol., 4 (1), 1-5, 2015 URL: http://www. isicenter.org/fulltext/paper-353.pdf

13. Министерство образования и науки Республики Адыгея [Электронный ресурс]: офиц. сайт. Режим доступа: http://adygheya.minobr.ru/node/1026. (дата обращения: 02.12.2016).

14. План-график мероприятий по повышению квалификации работников системы образования Республики Адыгея на 2017 год / Минобрнауки РА ГБУ ДПО РА «АРИПК». Майкоп: АРИПК, 2016. 28 с.

15. Министерство образования и науки Российской Федерации. Совещание министра образования и науки РФ О.Ю. Васильевой с ректорами педагогических вузов [Электронный ресурс]: офиц. сайт. Режим доступа: http:// минобрнауки.рф/новости/8951 (дата обращения: 15.11.2016).

\section{References}

1. Shekhmirzova A.M. O neobkhodimosti proektirovaniya novoy pedagogicheskoy sistemy $i$ realizatsii pedagogicheskoy tekhnologii v sootvetstvii s kompetentnostnym podkhodom [On the need to design a new pedagogical system and implement pedagogical technology in accor- 
dance with the competence approach]. Sovremennoe obrazovatel'noe prostranstvo: puti modernizatsii: materialy II mezhdunarodnoy zaochnoy nauchno-prakticheskoy konferentsii. 5 dekabrya 2011 [Modern Educational Space: Ways of Modernization: Materials of the II International Correspondence Scientific and Practical Conference. December 5, 2011] / Scientific Editor M.V. Volkova. Cheboksary: SRI of Pedagogy and Psychology, 2011. 222 p., pp. 214-218.

2. Shekhmirzova A.M., Pshizova A.R. Metodologicheskie problemy vuzovskoy praktiki formirovaniya universal'nykh kompetentsiy (na primere pedagogicheskikh $i$ ekonomicheskikh napravleniy podgotovki) [Methodological problems of the university practice of forming universal competencies (on the example of pedagogical and economic areas of training)]. V mire nauchnykh otkrytiy [In the world of scientific discoveries]. No. 11.4 (71), 2015, pp. 1498-1508.

3. Averin S.P. Social'no-pedagogicheskij monitoring kak uslovie sovershenstvovanija dejatel'nosti IPK RO po povysheniju kvalifikacii rabotnikov obrazovanija v regione [Socio-pedagogical monitoring as a condition for improving the activities of the PKI RO on improving the skills of educators in the region]. Krasnoyarsk: IPK RO, 2001. $154 \mathrm{p}$.

4. Informacionnoe Agentstvo Rossii «TASS» [The Russian Information Agency “TASS"]. http://tass.ru/opinions/interviews/3615515

5. Perechen'poruchenij po itogam zasedanija Gosudarstvennogo soveta po voprosam sovershenstvovanija sistemy obshhego obrazovanija ot 23.12. $2015 \mathrm{~g}$. [List of instructions on the results of the meeting of the State Council on improving the general education system from 23.12. 2015]. http://www.kremlin.ru/events/state-council/51143

6. FGBNU «Institut strategii razvitija obrazovanija Rossijskoj akademii obrazovanija» [Institute for the Development Strategy of Education of the Russian Academy of Education]. http://www.instrao.ru

7. Denise Vaillant Teacher training in Latin America. Models and tendencies conference «Priorites-Priorities-Prioridades» [Denise Vaillant Teacher training in Latin America. Models and tendencies conference "Priorities-Priorities-Prioridades"]. November 15 to 17, 2000 Paris. 20 p. http://www.denisevaillant.com/articulos/2000/priorites2000ENG.pdf 
8. Ellis A.K. Research on Educational Innovations / A.K. Ellis, J.T. Fouts. N.Y: Eye On Education: Princeton Junction, 1993, pp. 189-202.

9. Hassard I. Creating Cooperative Learning Environments. Menlo Raghk. California, 1987. 92 p.

10. Hassard J. Creating Cooperative Learning Invironment. Menlo Park, California, 1997. $126 \mathrm{p}$.

11. Johnson D.W., Johnson R.T. Learning together and alone: Cooperation, competition and individualization. Englewood Cliffs (N.3.), 1980.

12. Sayyida F.E., Attaollah G.K. Comparative Study of Information and Communication Technology Development Strategies in Primary Education of America, Australia and Iran. International Journal of Basic Sciences \& Applied Research. Vol., 4 (1), 1-5, 2015. http://www.isicenter.org/fulltext/paper-353.pdf

13. Ministerstvo obrazovanija i nauki Respubliki Adygeja [Ministry of Education and Science of the Republic of Adygea]. http://adygheya. minobr.ru/node/1026

14. Plan-grafik meroprijatij po povysheniju kvalifikacii rabotnikov sistemy obrazovanija Respubliki Adygeja na 2017 god [Schedule of activities for the improvement of professional skills of the employees of the educational system of the Republic of Adygea for 2017] / Ministry of Education and Science of the Republic of Armenia, ARPK. Maykop: ARIPK, 2016. 28 p.

15. Ministerstvo obrazovanija i nauki Rossijskoj Federacii. Soveshhanie ministra obrazovanija i nauki RF O.Ju. Vasil'evoj s rektorami pedagogicheskih vuzov [Ministry of Education and Science of the Russian Federation. Meeting of the Minister of Education and Science of the Russian Federation O.Yu. Vasilieva with rectors of pedagogical universities]. http://минобрнауки.рф/новости/8951

\section{ДАННЫЕ ОБ АВТОРАХ}

Шехмирзова Анджела Мухарбиевна, доцент кафедры общей педагогики, кандидат педагогических наук, доцент; преподаватель Центра развития педагогического и психологического образования АРИПК; член Республиканского экспертного совета по вопросам формирования и функционирование ин- 
новационной инфраструктуры в сфере образования при Министерстве образования и науки Республики Адыгея Адыгейский государственный университет; Адыгейский республиканский институт повышения квалификации ул. Первомайская, 208, г. Майкоп, Республика Адыгея, 385000 , Российская Федерация; ул. Ленина, 15, г. Майкоп, Республика Адыгея, 385000, Российская Федерация andsheh@mail.ru

Грибина Людмила Владиславна, доцент кафедры русского языка и методики преподавания факультета педагогики и психологии, кандидат педагогических наук, доцент Адыгейский государственный университет ул. Первомайская, 208, г. Майкоп, Республика Адыгея, 385000 , Российская Федераичия

Тугуз Фатима Анзауровна, доцент кафедры философии, социологии и педагогики

Майкопский государственньй технологический университет ул. Первомайская, 191, г. Майкоп, Республика Адыгея, 385000 , Российская Федераичия

\section{DATA ABOUT THE AUTHORS}

Shekhmirzova Andzhela Muharbievna, Assistant Professor Department Of General Pedagogy, Ph.D., Assistant Professor Adyghe State University; Adyghe Republican Institute of Advanced Studies

208, Pervomaiskaya Str., Maikop, Adygea Republic, 385000, Russian Federation; 15, Lenin Str., Maikop, Adygea Republic, 385000, Russian Federation

andsheh@mail.ru

SPIN-code: 2128-2638

ORCID: 0000-0002-4395-8337

ResearcherID: M-6139-2017 
Gribina Lyudmila Vladislavna, Assistant Professor Department of General Pedagogy, Ph.D., Assistant Professor Adyghe State University 208, Pervomaiskaya Str., Maikop, Adygea Republic, 385000, Russian Federation

Tuguz Fatima Anzaurovna, Assistant Professor Department of Philosophy, Sociology and Pedagogy, Ph.D. Maikop State Technological University 191, Pervomaiskaya Str., 191, Maikop, Adygea Republic, 385000 Russian Federation 